\title{
Association of Thyroid Hormone Levels Among Type 2 Diabetic Patients Attending a Tertiary Care Hospital
}

\author{
Khan NZ ${ }^{1}$, Muttalib MA², Sultana $\mathrm{GS}^{3}$

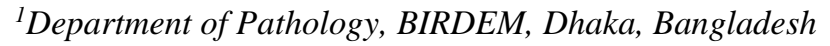 \\ ${ }^{2}$ Department of Biochemistry, BIRDEM, Dhaka, Bangladesh \\ ${ }^{3}$ Department of Clinical Pathology, BIRDEM, Dhaka, Bangladesh \\ e-mail:nadiazebin@yahoo.com
}

\begin{abstract}
Type 2 diabetes mellitus (T2DM) and thyroid disorders (TD) are the two most common endocrine disorders in clinical practice. They show mutually influence on each other. Unrecognized thyroid disorders may adversely affect the metabolic control and add more risk to an already predisposing type 2 diabetes mellitus. The objective of this study was to find out the association of thyroid hormone levels in patients with type 2 diabetes mellitus. This cross sectional study was conducted in the department of Biochemistry and outpatient department of Endocrinology of Bangladesh Institute of Research and Rehabilitation in Diabetes, Endocrine and Metabolic Disorders, Dhaka, Bangladesh (BIRDEM) General Hospital, Bangladesh from July 2014 to June 2015. A Total of 200 patients were selected by applying inclusion and exclusion criteria. Of them, 115 were type 2 diabetic subjects and 85 were non diabetic. Diabetic patients were diagnosed according to WHO criteria from their previous medical records. All patients were underwent thyroid function tests; free thyroxine (FT4), free tri-iodothyronine (FT3) and serum TSH (thyroid stimulating hormone). Presence of TD in T2DM and non-DM patients were estimated. Comparison of all demographic characteristics and biochemical parameters were done among the groups. The percentage of TD in type 2 diabetic patients was $23.5 \%$ and in non diabetic subjects was $12 \%$. Serum FT3 and serum FT4 did not show any significant difference among the groups. Type 2 diabetic patients with thyroid disorders had more elevated level of serum TSH level than those who were non diabetic subjects with TD. Thyroid disorders were significantly higher in female, overweight and obese subjects. Patients with TD had strong association with family history of TD. This study showed that the presence of TD in type 2 diabetes mellitus was very high. Regular screening for thyroid disorders in type 2 diabetic patients specially serum TSH level is recommended.
\end{abstract}

\section{Introduction}

Diabetes mellitus is a group of metabolic disorders characterized by hyperglycemia either defect in insulin secretion or insulin action or both. It may present different micro and macro vascular complications such as coronary artery disease, cerebrovascular disease, retinopathy, neuropathy, nephropathy etc. with different level of severity. ${ }^{1}$ Worldwide 387 million people were estimated to have DM in 2014 and this number is expected to rise up to 592 million by $2035 .^{2}$

$\mathrm{DM}$ is becoming pandemic in developing countries. Magnitude of this disease in Bangladesh is also increasing. Bangladesh is one of the top 10 countries estimated to have the highest numbers of people with DM. ${ }^{3}$ In Bangladesh a recent meta-analysis showed, prevalence of DM increased substantially, from 4\% in 1995 to 2000 and 5\% from 2001 to 2005 and $9 \%$ from 2006 to $2010 .{ }^{4}$ The prevalence of DM in Bangladesh was estimated 6.34\%. ${ }^{2}$

T2DM and TD mutually influence each other. ${ }^{5}$ TD is a spectrum of disorders of the thyroid gland which manifests subclinical or overt hyper or hypothyroidism and reflected in the circulating level of TSH. ${ }^{6}$ Hyperthyroidism is defined when there is low serum TSH with normal or elevated serum FT3 or FT4. Hypothyroidism is defined when there is elevated serum TSH with normal or low serum FT3 or FT4. The prevalence of TD 
in general population was estimated $6.6 \% .^{7}$ In National Health and Nutrition Examination Survey (NHANES), on 17,353 subjects representing the US population, hypothyroidism was to be found $4.6 \%$ and hyperthyroidism was $1.3 \% .^{8}$

DM influences thyroid function in two sites, first at the level of hypothalamic control of TSH release and secondly at the conversion of $\mathrm{T} 4$ to T3 in the peripheral tissue. ${ }^{9}$ Marked hyperglycemia causes reversible reduction of activity and hepatic concentration of $\mathrm{T}_{4-5}$ deiodinase following low serum FT3, elevated reverse T3 and Low, normal or high FT4. ${ }^{9}$

In Punjab, a study reported percentage of hypothyroidism was $23.5 \%$ (15\% subclinical and $8.75 \%$ overt) and hyperthyroidism $6.25 \%$ among 80 T2DM patients. ${ }^{6}$ Radaideh et al ${ }^{10}$, in their study reported percentage of TD was $12.5 \%$ in T2DM patients in Jordan. In Nepal, a study reported 29\% abnormal thyroid hormone level in T2DM patients. ${ }^{9}$ Devi in Manipur reported prevalence of thyroid abnormality was $24 \%$ in T2DM patients. In Bangladesh, there are few studies on thyroid disorders in diabetic subjects. Islam showed that the average FT3 level was significantly lower in the DM patients compared to non-DM subjects.

Thyroid hormones may control glycemic control in variety of actions on intermediary metabolism. Excess thyroid hormone promotes hyperglycemia by facilitating intestinal glucose absorption, increasing insulin clearance and enhancing glycogenolysis and gluconeogenesis.5 In diabetic patients, hypothyroidism may predispose hypoglycemia by reducing hepatic glucose output, gluconeogenesis and peripheral glucose utilization. ${ }^{13}$

The aim of this study was to find out the thyroid hormone levels among type 2 diabetic patients and to estimate the of thyroid disorders amongst them.

\section{Materials and Method}

This cross sectional study was conducted at the Department of Biochemistry and outpatient patient Department of Endocrinology, BIRDEM General Hospital during the period of July 2014 June 2015. The study was approved by Ethical Review Committee of Diabetic Association of
Bangladesh. A total of 200 patients were selected attending the outpatient department of Endocrinology after scrutinizing inclusion and exclusion criteria.

A structured questionnaire was used to collect data regarding age, sex, family history, socioeconomic etc. T2DM, and normoglycemia was diagnosed according to WHO criteria from the patients' medical records. Height and weight were recorded and body mass index (BMI) was calculated. With all aseptic precautions, $3 \mathrm{ml}$ venous blood was drawn from the anterior cubital vein in a disposal syringe and delivered in plain tube for estimation of serum TSH, FT3 and FT4. Serum was used to carry out all the tests. Study subjects were divided into 4 groupsGroup 1: Type 2 DM with TD; Group 2: NonDM with TD, Group 3: Type 2 DM without TD; Group 4: Non-DM without TD. For comparison of characteristics, Mean with standard deviation of serum TSH, FT3, FT4 were determined. Chisquare and ANOVA t-test were done for comparison of characteristics between type 2 diabetic and non diabetic subjects. All statistical tests were considered significant at the level of $\leq 0.05$ and were performed with the help of IBM SPSS (Statistical Package for Social Science) for windows (2013), version 22.0 (Armonk, NY, IBM corp.).

\section{Results}

A total number of 200 subjects were selected for the study. Out of them, 115 having type 2 diabetic and 85 were non diabetic. Of the 115 , T2DM with TD were 27, T2DM without TD were 88 . Amongst the 85 non diabetic, non-DM with TD were 11 and non-DM without TD were 74. Out of the 27 T2DM patients with TD, $25.9 \%$ were male and $74.1 \%$ female. Among 11 nonDM patients with TD, $27.3 \%$ were male and $72.7 \%$ female. Among the 88 T2DM patients without TD, $53.4 \%$ were male and $46.6 \%$ female. Among 74 non-DM patients without TD, 55.4\% were male and $44.6 \%$ female. Thyroid disorders were significantly higher in female subjects $(p=0.021)$ (table I). Among T2DM patients with TD, non-DM patients with TD, T2DM patients without TD and non-DM patients without TD; $37.0 \%, 27.3 \%, 9.1 \%$ and $5.4 \%$ had positive family history of TD and 63\%, 72.7\%, $90.9 \%$ and $94.6 \%$ had no family history of TD respectively. Family history of TD was 
significantly higher in both T2DM patients with TD and non-DM patients with TD $(p<0.001)$ (table I). The percentage of overweight and obese are $63 \%, 63.6 \%, 44.3 \%$ and $23 \%$ in the groups of T2DM with TD, non-DM with TD, T2DM without TD and non-DM without TD respectively. Overweight and obesity was significantly higher in both T2DM and non-DM patients with TD $(p<0.001)$ (table I).

Table I: Demographic characteristics of the study subjects

\begin{tabular}{cccccc}
\hline \multicolumn{1}{c}{$\begin{array}{c}\text { Group1 } \\
\text { Characteristic } \\
\text { T2DM with } \\
\text { TD } \\
(\mathrm{n}=27)\end{array}$} & $\begin{array}{c}\text { Group2 } \\
\text { Non-DM } \\
\text { with TD } \\
(\mathrm{n}=11)\end{array}$ & $\begin{array}{c}\text { Group3 } \\
\text { T2DM } \\
\text { without } \\
\text { TD } \\
(\mathrm{n}=88)\end{array}$ & $\begin{array}{c}\text { Group4 } \\
\text { Non-DM } \\
\text { without TD } \\
(\mathrm{n}=74)\end{array}$ & $p$ \\
\hline $\begin{array}{c}\text { Gender } \\
\text { Male }\end{array}$ & $7(25.9 \%)$ & $3(27.3 \%)$ & $47(53.4 \%)$ & $41(55.4 \%)$ & $0.021^{*}$ \\
Female & $20(74.1 \%)$ & $8(72.7 \%)$ & $41(46.6 \%)$ & $33(44.6 \%)$ & \\
& & & & & \\
Family & Of TD & & & & \\
history & & & & & \\
& $10(37.0 \%)$ & $3(27.3 \%)$ & $8(9.1 \%)$ & $4(5.4 \%)$ & $<0.001$ \\
Present & $17(63.0 \%)$ & $8(72.7 \%)$ & $80(90.9 \%)$ & $70(94.6 \%)$ & $*$ \\
Absent & & & & & \\
BMI(kg/m $\left.{ }^{2}\right)$ & & & & & \\
Normal & $10(37.0 \%)$ & $4(36.4 \%)$ & $49(55.7 \%)$ & $57(77.0 \%)$ & $<0.001$ \\
Overweight & $8(29.6 \%)$ & $6(54.5 \%)$ & $33(37.5 \%)$ & $13(17.6 \%)$ & $*$ \\
obese & $9(33.3 \%)$ & $1(9.1 \%)$ & $6(6.8 \%)$ & $4(5.4 \%)$ & \\
\hline
\end{tabular}

Statistical analysis was done by Chi-square test to compare among the groups. * Significant $(p \leq 0.05)$

Mean \pm SD of S. FT3 (pmol/L) was 2.01 \pm 2.22 , $1.85 \pm 2.18,1.85 \pm 0.84$ and $1.85 \pm 0.61$ in $\mathrm{T} 2 \mathrm{DM}$ with TD, non-DM with TD, T2DM without TD and non-DM without TD respectively. No significant difference was to be found among the groups ( $p>0.05$ ) (table II). Mean \pm SD of serum FT4 (pmol/L) was $17.11 \pm 20.92,17.39 \pm 19.86$, $15.46 \pm 3.66$ and $15.81 \pm 2.96 \mathrm{~T} 2 \mathrm{DM}$ with $\mathrm{TD}$, non-DM with TD, T2DM without TD and nonDM without TD respectively. No significant difference was to be found among the groups ( $p>$ 0.05 ) (table II). Mean \pm SD of serum TSH $(\mu \mathrm{IU} / \mathrm{L})$ was $25.29 \pm 62.15,7.14 \pm 5.27,3.22 \pm 1.30$ and $3.60 \pm 1.20$ in $\mathrm{T} 2 \mathrm{DM}$ with TD, non-DM with $\mathrm{TD}$, T2DM without TD and non-DM without TD respectively. There were significant difference among the groups and TSH was higher in type 2 DM with TD patients than in non-DM with TD patients $(p<0.05)$ (table II).
The percentage of TD in type $2 \mathrm{DM}$ patients is $23.5 \%$ and in non-DM subjects is $12 \%$. The percentage of TD in type $2 \mathrm{DM}$ patients was significantly higher than non-DM subjects (table III)

Table II: Biochemical findings of the study subjects

\begin{tabular}{|c|c|c|c|c|c|c|}
\hline Parameters & $\begin{array}{c}\text { Group1 } \\
\text { T2DM } \\
\text { with TD } \\
(\mathbf{n}=27)\end{array}$ & $\begin{array}{c}\text { Group2 } \\
\text { Non-DM } \\
\text { with TD } \\
(\mathrm{n}=11)\end{array}$ & $\begin{array}{c}\text { Group3 } \\
\text { T2DM } \\
\text { without } \\
\text { TD } \\
(\mathbf{n}=\mathbf{8 8})\end{array}$ & $\begin{array}{c}\text { Group4 } \\
\text { Non-DM } \\
\text { without } \\
\text { TD } \\
(n=74) \\
\end{array}$ & $\begin{array}{c}\text { Statistical } \\
\text { analysis }\end{array}$ & $p$ \\
\hline $\begin{array}{l}\text { S. TSH } \\
(\mu \mathrm{IU} / \mathrm{L})\end{array}$ & $\begin{array}{l}25.29 \pm 62 . \\
15\end{array}$ & $7.14 \pm 5.27$ & $\begin{array}{l}3.22 \pm 1.3 \\
0\end{array}$ & $3.60 \pm 1.20$ & $\begin{array}{l}\text { ANOVA } \\
\text { t-test }\end{array}$ & $\begin{array}{l}<0 \\
.00 \\
1 *\end{array}$ \\
\hline $\begin{array}{l}\text { S. FT3 } \\
(\mathrm{pmol} / \mathrm{L})\end{array}$ & $2.01 \pm 2.22$ & $1.85 \pm 2.18$ & $\begin{array}{l}1.85 \pm 0.8 \\
4\end{array}$ & $1.85 \pm 0.61$ & $\begin{array}{l}\text { ANOVA } \\
\text { t-test }\end{array}$ & $\begin{array}{l}0.9 \\
27 \\
\text { ns }\end{array}$ \\
\hline $\begin{array}{l}\text { S. FT4 } \\
(\mathrm{pmol} / \mathrm{L})\end{array}$ & $\begin{array}{l}17.11 \pm 20 . \\
92\end{array}$ & $17.39 \pm 19.86$ & $6.15 .46 \pm 3$. & $\begin{array}{l}15.81 \pm 2.9 \\
6\end{array}$ & $\begin{array}{r}\text { ANOVA } \\
\text { t-test }\end{array}$ & $\begin{array}{l}0.8 \\
18 \\
\text { ns }\end{array}$ \\
\hline
\end{tabular}

Statistical analysis was done by ANOVA t-test to compare among the groups. *=Significant $(p \leq 0.05), \mathrm{ns}=$ Not significant $(p>0.05)$.

Table III: Percentage of TD in T2DM and non-DM subjects

\begin{tabular}{lll}
\hline & $\begin{array}{l}\text { T2DM }(\mathbf{n}=115) \\
\text { No. }(\%)\end{array}$ & $\begin{array}{c}\text { Non-DM } \\
\text { No. }(\%)\end{array}$ \\
\hline Total TD & $27(23.5 \%)$ & $11(12 \%)$ \\
\hline
\end{tabular}

\section{Discussion}

The present study was designed as an analytical cross-sectional study. A total of 200 subjects, age 30-60 years were selected. Amongst them, 115 were type 2 diabetic and 85 were non diabetic subjects.

The previous study showed TD in female was $40.9 \%$ and in male $19.8 \% .{ }^{14}$ Other study showed TD in female was $71.87 \%$ and in male $28.12 \% .^{15}$ In the present study, amongst 27 T2DM patients with TD, $25.9 \%$ were male and $74.1 \%$ were female; of the 11 non-DM patients with TD, $27.3 \%$ were male and $72.7 \%$ female; out of the 88 T2DM patients without TD, $53.4 \%$ were male and $46.6 \%$ female and among 74 non-DM patients without $\mathrm{TD}, 55.4 \%$ were male and $44.6 \%$ female. Thyroid disorders were significantly higher in female subjects.

A study in India showed that $21.87 \%$ thyroid patients had positive family history of TD and $78.12 \%$ thyroid patients had negative family history. ${ }^{15}$ In the present study, among T2DM patients with TD, non-DM patients with TD, T2DM patients without TD and non-DM patients without TD; $37.0 \%, 27.3 \%, 9.1 \%$ and $5.4 \%$ had 
positive family history of TD respectively and $63 \%, 72.7 \%, 90.9 \%$ and $94.6 \%$ had no family history of TD respectively. Family history of TD was significantly higher in both T2DM patients with TD and non-DM patients with TD.

Jain et al found that most patients with T2DM with TD had BMI more than $30 . .^{15}$ in T2DM, $70.5 \%$ thyroid patients were overweight and obese. ${ }^{13}$ Finding of these study are consistent with the present study.

In Bangladesh, study showed that Mean \pm SD (pmol/L) of serum FT3 was $1.48 \pm 0.41$ in T2DM patients and $2.77 \pm 0.76$ in non-DM patients. ${ }^{12}$ In the present study, Mean \pm SD of serum FT3 $(\mathrm{pmol} / \mathrm{L})$ were $2.01 \pm 2.22,1.85 \pm 2.18,1.85 \pm 0.84$ and $1.85 \pm 0.61$ in T2DM with TD, non-DM with TD, T2DM without TD and non-DM without TD respectively. No significant difference was to be found among the groups.

Islam et al also found that Mean $\pm \mathrm{SD}(\mathrm{pmol} / \mathrm{L})$ of serum FT4 was $13.67 \pm 2.98$ in T2DM patients and $13.14 \pm 2.53$ in non-DM patients. ${ }^{12}$ In the current study, Mean \pm SD of S. FT4 $(\mathrm{pmol} / \mathrm{L})$ were $17.11 \pm 20.92,17.39 \pm 19.86,15.46 \pm 3.66$ and $15.81 \pm 2.96$ in T2DM with TD, non-DM with TD, T2DM without TD and non-DM without TD respectively. No significant difference was found among the groups.

Shashi et al showed Mean \pm SD of serum TSH $(\mu \mathrm{IU} / \mathrm{L})$ is $2.84 \pm 0.71$ and $19.34 \pm 3.51$ in non-DM and T2DM patients respectively. ${ }^{16}$ Another study showed that Mean \pm SD of serum TSH $(\mu \mathrm{IU} / \mathrm{L})$ was $2.88 \pm 0.283$ in non-DM patients and $7.6 \pm 1.27$ in $\mathrm{T} 2 \mathrm{DM}$ patients. ${ }^{17}$ In the present study, Mean \pm SD of S.TSH $(\mu \mathrm{IU} / \mathrm{L})$ were $25.29 \pm 62.15, \quad 7.14 \pm 5.27, \quad 3.22 \pm 1.30 \quad$ and $3.60 \pm 1.20$ in T2DM with TD, non-DM with TD, T2DM without TD and non-DM without TD respectively. There was significant difference among the groups and TSH was higher in T2DM with TD patients than in non-DM with TD patients.

The prevalence of thyroid disorders in general population was estimated $6.6 \% .^{7}$ It was found that TD was $12.5 \%$ in $\mathrm{T} 2 \mathrm{DM}$ patients in Jordan. ${ }^{10}$ A study in Nepal, reported that $29 \%$ abnormal thyroid hormone level in T2DM patients. ${ }^{9}$ In Manipur, percentage of thyroid abnormality was $24 \%$ in T2DM patients. ${ }^{11}$ In the present study, the percentage of TD in T2DM was found $23.5 \%$ where in non-DM patients was $12 \%$.

\section{Conclusion}

Worldwide, the prevalence of TD in T2DM is increasing day by day. Previous studies showed that it is higher in South Asian countries. In the present study, percentage of TD in T2DM was found $23.5 \% \%$ where in non-DM was $12 \%$. In T2DM patients, TD may go undiagnosed because the sign and symptoms of TD and DM are similar. So, it may be concluded that every T2DM patients should do routine check-up of thyroid function test, specially serum TSH.

Acknowledgement: Authors acknowledge the support of the Department of Endocrinology for allowing to perform thyroid function tests. They are also grateful to Prof. Dr. Subhagata Choudhury, Director, Laboratory Services, BIRDEM and Prof. Dr. Md Abu Sayeed, Department of Community Medicine, Ibrahim Medical College, Dhaka for their support and cooperation.

\section{References}

1. American Diabetes Association. Diagnosis and classification of diabetes mellitus. Diabetes Care. 2010; 33 ( suppl 1 ): S62-S69

2. International Diabetic Federation. IDF Diabetes Atlas. $6^{\text {th }}$ Edition revision 2014. Available from (online): www.idf.org/.../ 2014-11-13-IDF-DiabetesAtlas-rv.pptx.

3. Ahasan HAMN, Islam Z, Alam B et al. Prevalence and Risk Factors of Type 2 Diabetes Mellitus Among Secretariat Employees of Bangladesh. Journal of Medicine. 2011; 12(2): 125-130.

4. Saquib N, Saquib J, Ahmed T, Khanam MA Cullen MR. Cardiovascular diseases and type 2 diabetes in Bangladesh: a systematic review and meta analysis of studies between 1995 and 2010. BMC Public Health. 2012; (12): 434.

5. Hage M, Mira S, Sami T, Azar ST. Thyroid Disorders and Diabetes Mellitus. J Thyroid Res. 2011; 7:1-7.

6. Singh G, Gupta V, Sharma AK, Gupta, N. Frequency of thyroid dysfunction among diabetes in Punjabi population. Biological Forum - An International Journal. 2011; 3(1): 74-77. 
7. Patricia, Wu. Thyroid disease and diabetes. Clinical Diabetes. 2000; 18(1): 38-41.

8. Hollowell JG, Staehlin NW, Flanders WD et al. Serum TSH, T4, and thyroid antibodies in the United States population (1988 to 1994): National Health and Nutrition Examination Survey (NHANES III). J Clin Endocrinol Metab. 2002; 87(2): 489-99.

9. Bharat HD, Gangte D, Lalnunpui P, Devi I, Singh GW. Thyroid Status in Diabetes Mellitus. J Glycomics Lipidomics. 2013; 3: 106.

10. Radaideh AR, Nusier MK, Amari FL et al. Thyroid dysfunction in patients with type 2 diabetes mellitus in Jordan. Saudi Med J. 2004; 25(8): 1046-50.

11. Devi MA, Singh NS, Singh S. Thyroid hormone dysfunctions in type 2 diabetic patients in urban areas of Manipur. International Journal of Pharmaceutical Science Invention. 2013; 2(10): 7-9.

12. Islam S, Yesmine $\mathrm{S}$, Khan $\mathrm{SA}$, Alam NH, Islam S. A comparative study of thyroid hormone levels in diabetic and non-diabetic patients. Southeast Asian J Trop Med Public Health. 2008; 39(5): 913-6.
13. Kumar RA, Narasimhasetty KR, Lalitha R, Shetty SB. Prevalence of thyroid dysfunction among type 2 diabetes subjects in South India. International Journal of Clinical Cases and Investigations. 2013; 5(6): 93-100.

14. Celani, MF. Bonati, ME. Stucci, N. Prevalence of abnormal thyrotropin concentrations measured by a sensitive assay in patients with type 2 diabetes mellitus. Diabetes Res. 1994; 27(1): 15-25.

15. Jain, G. Marwaha, TS. Khurana, A. Dhoat, PS. Prevalence of thyroid disorders in patients of type 2 diabetes mellitus. Int J Med and Dent Sci. 2013; 2(2): 153-61.

16. Shashi, A. Devi, U. Singla, S. Association between hypothyroidism and metabolic syndrome in type 2 diabetic patients: a cross sectional study. International Journal of Basic and Applied Medical Sciences. 2013; 3(1): 98-109.

17. Vij, V. Chitnis, P. Gupta, VK. Evaluation of thyroid dysfunction among type 2 diabetic patients. Int $\mathbf{J}$ Pharm Bio Sci. 2012; 2(4): 150-155. 